\title{
Design of Electromagnetic Rail Powered Missile for Penetrating Missile Defense System
}

\author{
Hari Prasanna MANIMARAN ${ }^{1}$, Naga Manikanta KOMMANABOINA ${ }^{2}$, \\ Mastan Raja PAPANABOINA ${ }^{3}$
}

\author{
1,2,3Kaunas University of Technology, Studentu 56, Kaunas, Lithuania, \\ Emails: ${ }^{1}$ hari.manimaran@ktu.edu; ${ }^{2 n a g a . k o m m a n a b o i n a @ k t u . e d u ; ~}$ \\ ${ }^{3}$ mastan.papanaboina@ktu.edu
}

\begin{abstract}
Replacing chemical propellant and using electric power that generate the muzzle power to propel the rocket is done since 1846. There were productive research conducted to achieve velocity of $2000-3000 \mathrm{~m} / \mathrm{s}$, which cannot achieved using conventional propellant. These velocities are capable of penetrating the armor vehicles and high-density materials. Research is conducted to increase the velocity and stealth technology to penetrate missile defense system. However, the advanced technology capable of detecting from small drone to high velocity missile. This research give the conceptual design of the two-staged missile capable penetrating the defense shield using only kinetic energy by unconventional propulsion system. One stage act as the prey to the incoming missile and other system enter the shield with its velocity higher than any other interceptor missile. This missile uses Lorentz force to propel the projectile towards the target.
\end{abstract}

KEY WORDS: Electromagnetic rail; EMR missile; Interceptors; Infrared signature, Lorentz force; Missile defence system; Projectile

\section{Introduction}

The defense territory if shielded by missile defense system (MDS). This system monitor the incoming cruise missile, drones and other aerial vehicles. As the missile launched from enemy territory reaching the missile defense system shield, the heat signature of the exhaust captured by infrared (IR) satellite and the trajectory is sensed by the MDS radar. The velocity and flight path are measured using missile defense radar, counteract will be initiated using interceptor missile. Thus entering MDS is difficult and sometime impossible with the advanced MDS.

The design of new kind of missile varying velocity and without heat signature can counteract the interceptor missile launched from MDS batteries. Destroying any part of the MDS is crucial part in the penetration. Based on the case study on the conventional missile defense system working the electromagnetic rail powered missile is designed to counter and enter the shield to destroy the target.

\section{Working Principle}

The concept of launching the projectile towards the target from the second stage of the missile using electromagnetism is basic principle.

The construction of this missile has conventional first stage with solid propellant and unconventional second stage, which act as a launcher for second stage.

The electromagnetic launcher works on principle of Lorentz force. When a current $\mathbf{I}$ is flowing right angle to the magnetic field $\mathbf{B}$, the force $\mathbf{F}$ will generate right angle to both the current and magnetic field. $\ell \cdot$ is the length of the armature.

$\mathrm{F} \cdot=\cdot \mathrm{I} \cdot \ell \cdot * \cdot \mathrm{B}$

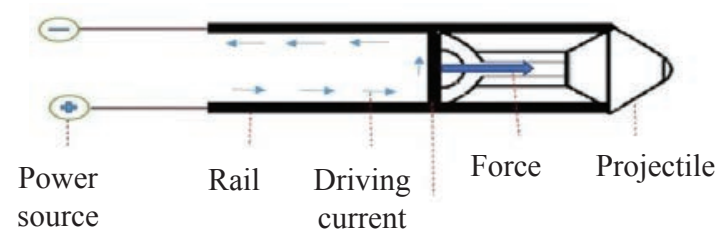

Armature

Fig.1. Current flow in the rail of the missile

Corresponding author. Tel.: 370-6-30-80-660.

E-mail address: hari.manimaran@ktu.edu 


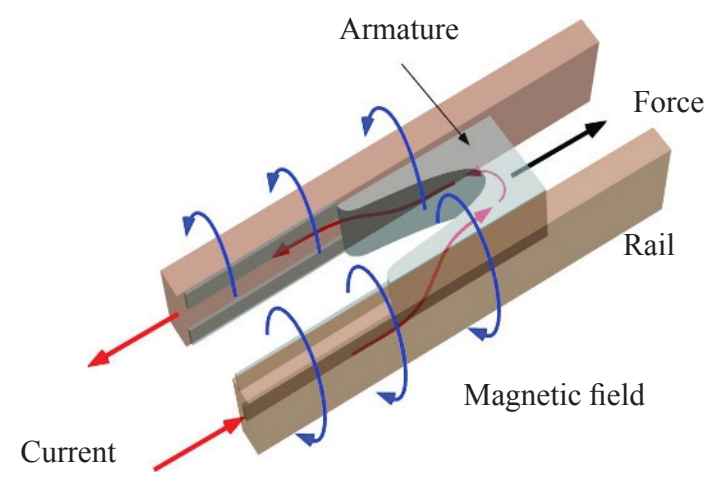

Fig.2. Lorentz force1

In the basic design rail is kept parallel to each other and longitudinal axis of the missile. As the length, extend from the solid motor to near nose cone. The rail made of conductive material such as copper. The power source of the launcher is capacitor bank, which transfer the energy required to propel the projectile.

Power source is the crucial part of the launcher that depend on the amount power applied is proportional to the propelling power. Larger current need to be applied to push the projectile for longer distance with higher kinetic velocity as the penetration of MDS required faster heatless motion.
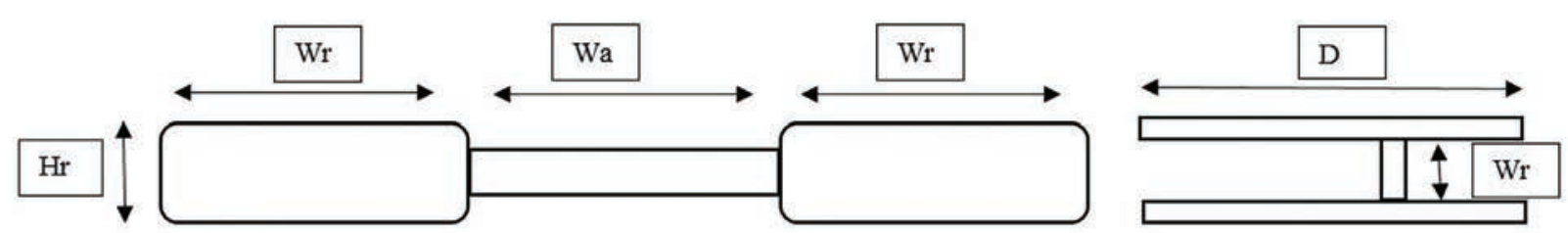

Fig.3.Schematic diagram of electromagnetic rail

$\mathrm{Wr}=$ width of the rocket rail;

$\mathrm{Hr}=$ height;

$\mathrm{D}=$ length of the rail;

$\mathrm{Wa}=$ distance separating rail.

The expression for the change of muzzle velocity over the time:

$$
\frac{d y_{\text {muzzle }}}{d t}=\sqrt{\frac{L^{\prime} D}{m} * I}
$$

$\mathrm{L}^{\prime}=$ inductance gradient;

$\mathrm{D}=$ length of the rail;

$\mathrm{I}=$ current;

$\mathrm{m}=$ armature mass.

Equation (2) gives the kinetic energy applied on the projectile:

$$
\begin{aligned}
\mathrm{KE} \cdot_{\text {muzzle }} & =\frac{1}{2} m \frac{d y_{\text {muzzle }}}{d t} \\
& =\frac{1}{2} L^{\prime} D I^{2}
\end{aligned}
$$




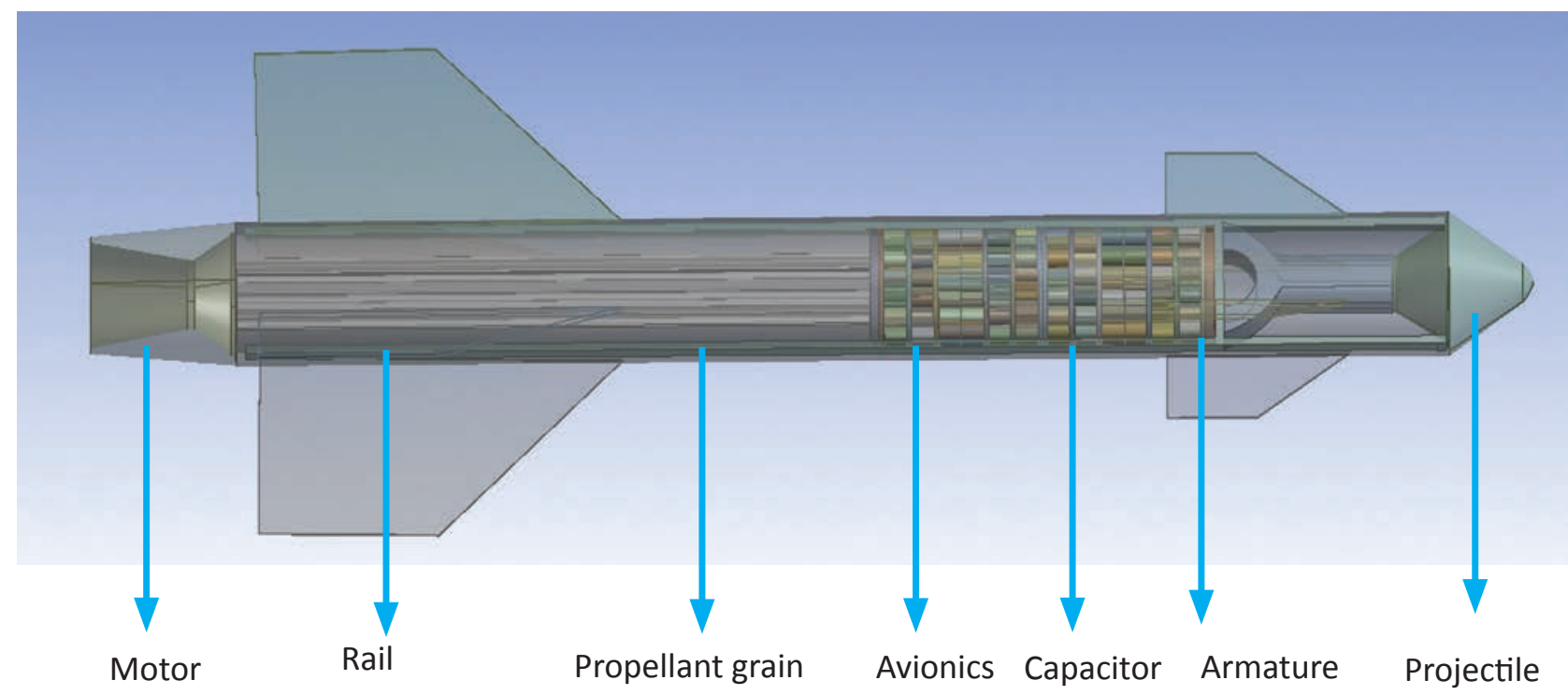

Fig.4. Parts of the missile

First stage: First stage of missile is conventional solid propellant motor uses Ammonium perchlorate based composite propellant. The grain geometry is internal burning tube and slot. The aluminium casing is used to reduce weight and insulation is done to separate the rail from the casing and fuel. Ignitor kept on the top of the first stage and avionics system proceeds the first stage.

Second stage: Second stage consists of copper rail running parallel to missile longitudinal axis; the high-power capacitor bank store all the power need to propels the projectile. The high-density armature, which slides in the gap between the rails. Armature completes the circuit and allows the current to flow in the circuit.

This current flow create the force to push the projectile. The injection system is employed to give initial push of the projectile otherwise, it creates arc and heats up the system. Projectile is made of rigid material such as titanium and the shape of the projectile is aerodynamically modified to thin sharp edge shape gives better performance and reduced drag during the motion. As it is not caring any control, propulsion, guidance system it can be thin enough to deflect the radar waves. As it completely rely on kinetic energy, it does not produce any heat signature.

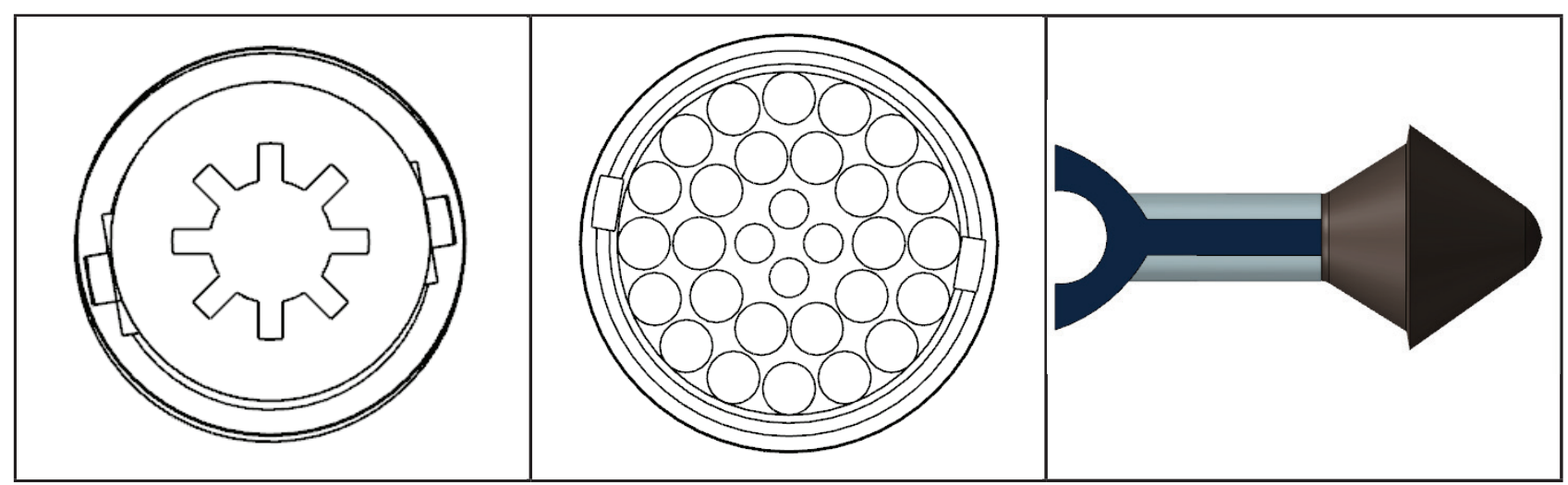

Fig.5. Grain geometry

Fig.6. Arrangement of capacitor

Fig.7. Projectile

Fins are used to control the stability and maneuver of the missile trajectorie at first and second stage. 


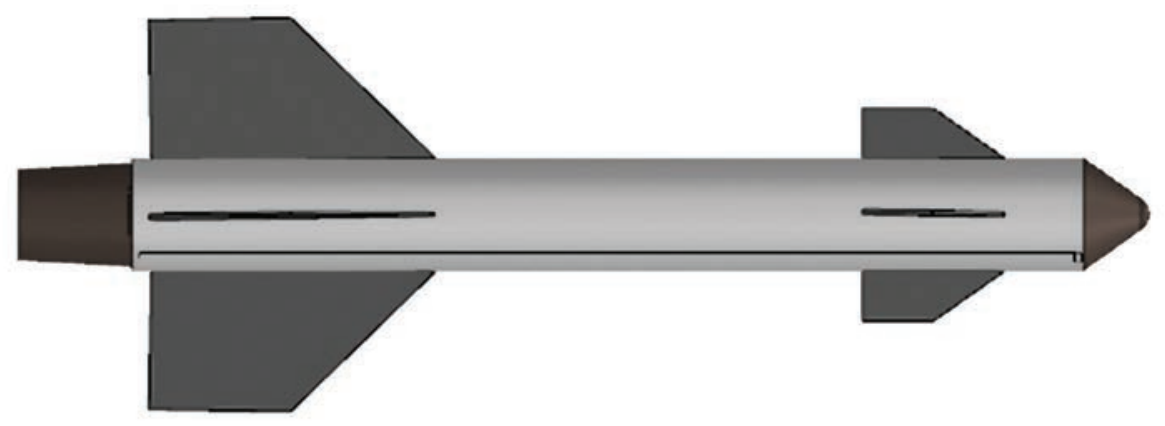

Fig.8. Side view of missile

Table 1

Missile specifications

\begin{tabular}{|c|c|}
\hline Total length & $14000 \mathrm{~mm}$ \\
\hline Diameter & $1300 \mathrm{~mm}$ \\
\hline Mass & $12000 \mathrm{~kg}$ \\
\hline speed & $830 \mathrm{~m} / \mathrm{s}$ \\
\hline Missile range & $400 \mathrm{~km}$ \\
\hline Rail length & $13250 \mathrm{~mm}$ \\
\hline Projectile length & $400 \mathrm{~mm}$ \\
\hline projectile range & $60 \mathrm{~km}$ \\
\hline Projectile speed & $1500 \mathrm{~m} / \mathrm{s}$ \\
\hline
\end{tabular}

\section{Mission segment}

Mission profile designed to destroy the particular element of the missile defence system. Multiple launch required to destroy the complete MDS. Critical elements of MDS is satellite, radar, interceptor batteries. Mostly the radar and batteries are the target for this kind of missile.

Missile is launched from the ground and the variant can be launched from aircraft. After the launch of the missile, the heat signature is captured by the infrared satellite and sends the signal to MDS system.

The MDS radar detect the trajectory of the incoming missile and signals to launch of interceptor missile. The interceptor is targeted towards the incoming missile. The velocity of interceptor coincide with the missile.

Missile approach warning system (MAWS) in our missile detect that the missile is locked with interceptor. Based on MAWS the control system alter the attitude of missile and point towards the target.

The injection system pushes the projectile. The high-energy current in the rail creates high kinetic energy that pushes the projectile towards the target. There is no propulsion system is used on the projectile so it does not produce any heat signature. The aerodynamic shape keeps the projectile hidden from radar detection. Due to its thin body, it produce less drag and move faster. The motion completely rely on kinetic energy to hit-to-kill target.

The interceptor missile hit the incoming missile but the projectile already ejected from the missile and travel higher speed then the initialisation of another interceptor missile. The electromagnetic propulsion gives higher muzzle energy than any other missile so the projectile can travel much faster. 


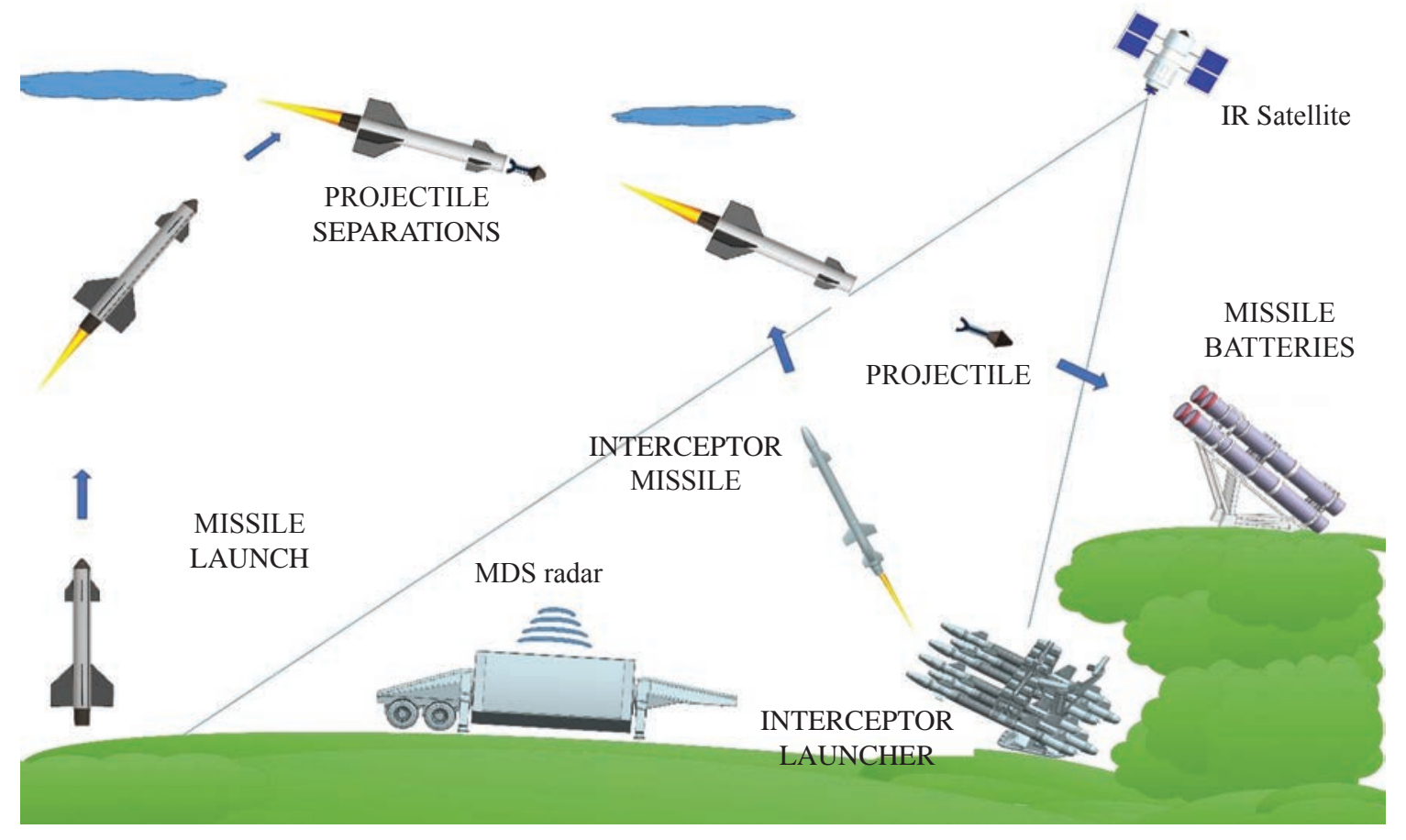

\section{Conclusions}

Fig.9. mission profile

The following results of our design:

- Hyper velocity projectile launched towards target by electromagnetic rail mounted on the missile;

- Trajectory is controlled by the control surface.

- Projectile travels on velocity produced by the electromagnetic rail avoids heat signature;

- Thin surface avoids aerodynamic drag and gives the additional stealth from radar signal.

- The first stage of missile act as prey target for the interceptor missile.

- Projectile escapes from interceptor missile and hits the target.

\section{Acknowledgements}

The design of this missile is inspired from the US navy railgun project designed by BAE SYTEMS and GENERAL ATOMICS. Authors thankful to Kaunas University of Technology online library and IEEE journals.

\section{References}

1. R.A. Merger. Railgun material science, Plasma Physics NRL review 2006.

2. McNab I. R, Stefani.F, Crawford.M.T, Erengil.M, Persad.C, Satapathy.S, Vanicek.H, Watt.T, and Dampier.C. Development of a Naval Railgun, IEEE EML 2004.

3. Harris, William. How Rail Guns Work, HowStuffWorks. Archived from the original on 17 March 2011. Retrieved 2011-03-25.

4. Lehmann.P, Peter.H, and Wey.J. First Experimental Results with the ISL 10 MJ DES Railgun PEGASUS, IEEE transactions on magnetics, vol. 37, no.01, January 2001.

5. Ian R. McNab, IEEE, Scott Fish, and Francis Stefani. Parameters for an Electromagnetic Naval Railgun, IEEE transactions on magnetics, vol. 37, no.01, January 2001.

6. Lehmann.P, Reck.B, Vo.M.D and Behrens.J, Acceleration of a Suborbital Payload Using an Electromagnetic Railgun, IEEE transactions on magnetics, vol. 43, no.01, January 2007.

7. Jerome T. Tzeng, IEEE Dynamic Response of Electromagnetic Railgun Due to Projectile Movement, IEEE transactions on magnetics, vol. 39, no.01, January 2003.

8. Multiple stage Railgun, United States Patent: 4,343,223, Aug. 10, 1982.

9. Missile Defense System, United States Patent: 5,400,688, Mar. 28, 1995.

10. Andrew M. Sessler, John M. Cornwall, Bob Dietz, Steve Fetter, Sherman Frankel, Richard L. Garwin, Kurt Gottfried, Lisbeth Gronlund, George N. Lewis, Theodore A. Postol, David C. Wright. A Technical Evaluation of the Operational Effectiveness of the Planned US National Missile Defense System, April 2000. 